\title{
Psychology and interviewing: What direction now in our quest for reliable
} information?

Gavin E. Oxburgh, Department of Psychology, Teesside University, UK.

Coral J. Dando, Department of Psychology, Lancaster University, UK.

\begin{abstract}
The contribution of psychological theory and empirical research to investigative interviewing worldwide over the past 25 years is indisputable. The interviewing of both suspected offenders and witnesses (adults and children) owes much to those pioneers who have driven the well-documented radical shift in modus operandi, to both the processes and procedures associated with these complex skills. In the UK, psychologists and police officers have contributed both individually and collaboratively, to facilitate the current world leading 'search for the truth' approach. However, this paper argues that in order to stay ahead of the game, the field of investigative interviewing (suspect and witness) must continue to evolve in such a manner that not only protects and fosters the important practitioner/academic relationship, but which ensures that future directions are driven by empirical research, with recourse to emergent theory.
\end{abstract}




\section{Introduction}

It is generally accepted that information is the lifeblood of any criminal investigation (Milne \& Bull, 1999). In many countries, one of the most common methods of eliciting information is by way of an investigative interview, during which individuals are provided with an opportunity to explain the nature of their involvement in an event, be they witnesses, victims, and/or suspects. It is internationally acknowledged that an interview, whether witness or suspect is a complex verbal and social interaction, during which an investigator is duty bound to systematically 'search for the truth'. In England and Wales, this is carried out using a model of interviewing known as the PEACE model, which is a mnemonic acronym for the recommended phases of the interview process (Preparation and planning, Engage and explain, Account, Clarify and challenge, and Evaluation of the interview). This model provides a planned, ethical and fair means of interviewing, and encourages interviewers to remain open-minded at all times, whilst actively engaging with interviewees to obtain accurate and reliable information. On completion, interviewers are encouraged (indeed it is expected) to identify further opportunities that may further the investigation and they should also review their interviewing skills as part of their ongoing professional development.

This world leading approach owes much to both the psychological literature, and those who have pioneered its application. Together they have guided the well documented shift of modus operandi in the field of investigative interviewing over the past 25 years. However, despite the fact that the UK is viewed as 
signaling the way, in terms of the application of psychological research and theory to this aspect of the investigatory process, it is our contention that in order to continue to stay 'ahead of the game', even more needs to be done. Here, we briefly discuss two distinct but interrelated areas, namely witness/victim and suspect interviewing. We argue that both must continue to evolve, suggest how they might do so, and that this process must be driven by emergent theory and contemporary empirical research.

Acknowledging past achievements is not sufficient. Rather, enhancing the efficacy of an interview should be a continual quest, and that practitioners and psychologists must maintain and foster professional relationships in a supportive, but nonetheless critically enquiring environment in order to assist the process of bringing offenders to justice, and protecting the innocent.

\section{Interviewing witnesses and victims}

Since the introduction of the PEACE model of interviewing in the early 1990s, the UK's investigative interview model (specifically England \& Wales) has advocated the use of the Cognitive Interview (CI) procedure (see Fisher \& Geiselman, 1992 for a review) for retrieving information from co-operative interviewees (heron referred to as witnesses). Without doubt, the $\mathrm{CI}$ is one of the utmost researched and generally accepted methods of enhancing witness memorial performance. Described as "an innovative interviewing technique based on extant psychological theory and research examining the retrieval of information from memory" (Milne \& Bull, 1999, p. 184), the CI has been 
fundamental in changing the manner in which witness information is elicited by police investigators, and continues to direct both the practitioner and academic literature in this domain .

Originally presented in the mid 1980s (Geiselman et al., 1984), the CI has continued to evolve over subsequent years culminating in the enhanced cognitive interview (ECI), which is the current procedure. This process is well documented, having been reported in a series of empirical research papers, and books (Fisher \& Geiselman, 1992) and commented on extensively elsewhere (see Milne \& Bull, 1999), hence this will not be discussed further here. Instead, we concern ourselves with considering how the CI and ECI, with recourse to contemporary memory theory and some of the most recent empirical research, might further evolve to contend with the increasing demands of the UK criminal justice system (CJS). We ask how the CI can move forward into the $21^{\text {st }}$ century in such a manner so as to maintain its position as a world leading applied investigative interview procedure? In seeking to answer this question, albeit only in part, we briefly consider two of the mnemonic components, namely change temporal order (CTO) and mental reinstatement of context (MRC).

The CI was devised as a practical forensic tool, but in the 25 years since its initial development, and the 18 years following its implementation as part of the PEACE model, it is the case that both researchers and practitioners have consistently raised a number of concerns. These have culminated in a body of empirical literature suggesting a need to modify the technique (e.g. Kebbell \& Wagstaff, 1996; Milne \& Bull, 1999; Davis et al., 2005). Arguably, one of the most 
worrying aspects of the emergent literature, and one which has been fundamental in driving the recent paradigmatic shift toward investigating the efficacy of various modifications of the $\mathrm{CI}$, is its practical application. By this we mean, how the procedure is perceived and ultimately administered by those in the UK whose task it is to interview witnesses.

The $\mathrm{CI}$ is a homogenous procedure, comprising a number of individual components, each of which are included to maximize opportunities for the accurate retrieval of witnessed episodes. However, there is much to indicate that police officers' application of the $\mathrm{CI}$ is patchy. That is, the procedure is often not implemented at all, and/or some of the constituent components are not regularly applied, and/or the componential instructions given by the interviewer are sometimes unclear/incomplete (e.g., Clarke \& Milne, 2001; Dando, Wilcock, \& Milne, 2009; Clifford \& George, 1996; George, 1991; Longford 1996). Furthermore, officers' perceive the $\mathrm{CI}$ to be time consuming and cumbersome, and often report finding some of the individual components difficult to administer (e.g., Dando, Wilcock, \& Milne, 2008; Kebbell, Milne, \& Wagstaff, 1999; Wright \& Holliday, 2005).

This is concerning, and it has previously been argued that consideration should be given to modifying some of the $\mathrm{CI}$ components in terms of adding to the $\mathrm{CI}$ 'tool box' to account for the aforementioned findings, and also the increasing demands being placed on the police service in terms of increased workload and time constraints (e.g., Davies, McMahon, \& Greenwood, 2005; Dando et al., 2009; Dando, Wilcock, Henry, \& Milne, 2009). Additionally, it is our contention that 
witness interviewing per se is likely to be afforded far more attention in the future, as has occurred with suspect interview practices and procedures in the 1980/1990s. Should this be the case, the CJS may be leaving itself open to criticism in terms of the accuracy and ultimately the admissibility of eyewitness information elicited in a manner that falls foul of the current model, or which may be counter to contemporary psychological theory and empirical research pertaining to the retrieval of episodic information from long term memory.

Change Temporal Order (CTO)

Not only does CTO appear to be one of the lesser used CI components, but when it is implemented, research has suggested that the componential instructions are often poorly executed, with both occurrences having the potential to mitigate and/or interfere with memorial performance (e.g. Clarke \& Milne, 1999; Dando et al., in press; 2009; Kebbell et al., 1999; Memon et al. 1994). When undertaking a CTO retrieval, witnesses are usually instructed to attempt retrieval in a backwards order (see Fisher \& Geiselman, 1992). Included as a method of disrupting script-based retrieval, proponents suggest that: (i) it mitigates the negative impact that schematic/script-based organisation of memory can have by preventing the retrieval of events based on their typical temporal sequence (e.g., Schank \& Abelson, 1977), and (ii) that it facilitates previously inaccessible memories by encouraging witnesses to use an unusual mode of retrieval, which may increase the probability of additional item recall (Bower, 1967). 
Crime-related scripts have been shown to be a significant source of gap-filling errors of commission (including information that has not been experienced) and omission (failing to report experienced events that appear not to 'fit' a typical crime event) in eyewitness performance (Greenberg, Wescott \& Bailey, 1988; Holst \& Pezdek, 1992; Tuckey \& Brewer, 2003), and the role of scripts in understanding and organizing material in memory has received empirical support (e.g., Mandler, 1984; Pezdeck et al., 1989). Although CTO has received limited empirical validation, a review of the eyewitness literature reveals a mixed picture. Some researchers have found CTO to be an effective method for eliciting extra information (Boon \& Noon, 1994; Whitten \& Leonard, 1981), whilst others have found it no more effective than an additional free recall or try harder retrieval attempt (Milne \& Bull, 1999; Memon, Cronin, Eaves, \& Bull, 1996). More recently, CTO has been found to increase erroneous recall, resulting in significant reductions in memorial accuracy/performance, not only for unscripted mock crimes (Dando, et al., 2009a; 2009b; Davis et al., 2005), but arguably more importantly, for scripted crime events (Dando \& Ormerod, 2009; Dando, Ormerod, Wilcock, \& Milne, 2010).

While script-based accounts of memory predict benefits from CTO, two contemporary memory models, namely Context Maintenance and Retrieval (CMR; Polyn, Norman \& Kahana, 2008), and Population Dilution (PD; Lansdale \& Baguley, 2008) appear to imply negative effects. In brief, temporal clustering is central to CMR in that a search through memory is guided by, among other things, an internally maintained temporal context. Disrupting that context by asking witnesses to recall an event in an 'unnatural' manner may negatively 
impact memorial performance (see Dando et al., 2010; Dando \& Ormerod, 2009). Equally, PD provides a compelling mathematical model, which suggests that recall performance is a function of the relative proportions of three types of memory trace, namely 'C' (correct) 'E' (inaccurate) 'W' (null: completely false information, or confabulations). Where access to inaccurate and confabulated traces increases, the number of correct traces is diluted resulting in performance reductions.

The fact that CTO has been associated with increased confabulations, indicates that witnesses may have been reporting, rather than suppressing, null (W) traces. It may well be that the cognitive demands associated with retrieving information backwards may have impeded participants' ability to exercise report option over the $\mathrm{W}$ traces (Goldsmith, Koriat, \& Pansky, 2005). That evidence to support the application of CTO appears not to be forthcoming demands further consideration. Given the increased sophistication of cognitive models of longterm memory, practical methods for enhancing witness recall must surely reflect these advances. Research is now necessary to advance our understanding of the efficacy of CTO, and the nature of its contribution to the CI superiority effect as an additional retrieval strategy and/or as method of limiting script guided recall.

\section{Mental Reinstatement of Context (MRC)}

Turning to the MRC technique, unlike CTO, the beneficial effect of mentally recreating both the psychological and environmental context within which a to-be-remembered event (TBR) has received much empirical support in 
the eyewitness domain (e.g. Davis et al., 2005; Emmett, Clifford, \& Gwyer, 2003; Memon \& Bruce, 1995; Milne \& Bull, 1999). Indeed, MRC is generally accepted as being one of the most effective of the CI mnemonics. Hence, our primary concerns here are that MRC is time consuming (see Fisher \& Geiselman, 1992) and, as such, the technique is often not applied. Moreover, when it is, the instructions are often less than complete. In addition, if retrieval cues provided by the interviewer are incompatible with the TBR event, which is likely to be the case in light of the current interview training, which emphasizes the use of generic cues, it has been suggested that these have the potential to impair, rather than facilitate accurate and complete recall (e.g., see Dando et al., 2009; Rosenbluth-Mor, 2001). And, in forensic settings where interviewers often conduct repeat interviews, with either the same or different witnesses of one event, it may be that there also exists the potential to inadvertently introduce post-event information during MRC. By this we mean that interviewers may subsume information gleaned from earlier witnesses, and inadvertently introduce it in subsequent interviews. This is a a particular concern in the case of less experienced interviewers, who have only undergone basic training.

In an attempt to enhance the practicability of MRC, while retaining its benefits reducing opportunities for providing incompatible retrieval cues and introducing post event information, a novel Sketch $M R C$ has recently been devised and introduced. Sketch MRC places the onus on each individual witness to provide their own retrieval cues in that they are free to draw what is salient to them (see Dando et al., 2009 for a full description). Initial findings suggest that it may be a useful addition to the CI tool box in terms of offering another technique 
for time critical situations, and eliminating interviewer contamination of the MRC process, so lessening the number of situations that might allow the introduction of incompatible retrieval cues and post event information.

Initial empirical research with adults, comparing an interview procedure that incorporated a sketch MRC to one with a traditional MRC and a control, has revealed promising results. The Sketch MRC interview procedure was found to: (i) significantly reduce interview duration, thereby enhancing its viability as a useful tool for interviewers ; (ii) significantly reduce confabulated (completely false) recall, and; (iii) have had no deleterious effect on other memorial measures (Dando et al., 2009; 2010). To date, the programme of research pertaining to the Sketch MRC is in its infancy, and it should also be borne in mind that it is not without limitations. Notwithstanding, the picture that emerges shows much promise. Indeed initial results of further empirical evaluations of the technique, in more ecologically valid circumstances and with other populations (children and older adults, currently being conducted by the second author), indicate the robustness of these initial findings. We argue that this emerging literature would now benefit greatly from further academic and practitioner validation.

\section{Interviewing suspected offenders}

As is the case with witnesses and victims, successful interviews with offenders are fundamental in achieving justice in society (Milne, Shaw \& Bull, 2009). McGurk et al. (1993) argued that the ultimate objective of a police 
interview is to obtain accurate and relevant information from suspected offenders. Previous academic research has measured and analysed various aspects of interviews, including: (i) question types (for a review see Oxburgh, Myklebust \& Grant, 2010; Oxburgh, Ost \& Cherryman, 2010); (ii) effectiveness of the PEACE model of interviewing (e.g., Clarke \& Milne, 2001), and; (iii) the competency of interviewing officers (e.g., Baldwin, 1992a; 1993; Pearse \& Gudjonsson, 1999). According to this literature, a good 'quality' interview from which reliable information is obtained appears to be one in which: a) appropriate questioning techniques are used; b) the interviewers are appropriately trained, and; (c) interviewing officers use an empathic (humane) interviewing style.

Questioning techniques

Unfortunately, research with both witnesses and suspects has generally shown that poor questioning techniques by interviewers are routine, with interviewers regularly using closed, direct, leading and suggestive questions (sometimes known as inappropriate questions) during interviews. Conversely, the use of open or probing questions (sometimes known as appropriate questions) appear to be used infrequently (e.g. Baldwin, 1992a; 1993; Davies, Westcott \& Horan, 2000; Lamb, Hershkowitz \& Sternberg, 1996a; Myklebust \& Bjorklund, 2006; Oxburgh, et al., 2010). Further, when considering the ratio of open to closed questions, many researchers have found that the open-closed ratio (OCR) can be as high as 1:50 (Davies et al., 2000), indicating that for every one open question asked during an interview, interviewers asked 50 closed questions. 
Others have found the OCR to be much lower (e.g. 1:9, Fisher, Geiselman \& Raymond, 1987; 1:9, Myklebust \& Bjorklund, 2006; and 1:23, Oxburgh, et al., 2010).

However, in one recent study, which used a qualitative, 'think aloud' methodology, Griffiths, Milne and Cherryman (submitted) found that the development of questioning techniques used by UK police officers had been enhanced $^{1}$. This study appeared to indicate that officers showed high levels of understanding regarding officers' recognition of different question types. Interestingly, Griffiths et al., also found that officers favoured the use of probing questions in order to obtain detailed accounts from suspects. However, this was not the case with witnesses, where probing questions were used less appropriately. Another recent UK study, where real-life interviews of child sexual victims were analysed, found similar results. Indeed, Phillips, Oxburgh, Gavin \& Myklebust (submitted) found that officers used an equal proportion of appropriate and inappropriate questions during interviews. Whilst this is a welcome improvement from previous studies, Phillips et al., (submitted) found, similar to Griffiths et al., (submitted) that from questions categorised as appropriate, the most frequently asked were probing/identification, with open questions being asked considerably less .

Regardless, there is overwhelming acceptance that using appropriate forms of questions are the most productive, in terms of gathering information and

\footnotetext{
${ }^{1}$ Note: Officers in this study had completed advanced suspect or witness interview courses.
} 
encouraging interviewees to freely recall events (see Pipe, Lamb, Orbach \& Esplin, 2004 for a review of the literature). However, although there appears to have been some limited improvement recently (e.g. Griffiths et al., submitted; Phillips et al., submitted), in general terms, the levels and usage of closed (and other inappropriate) questions are still unacceptably high. The obvious question that arises is why are inappropriate questions continually used?

One explanation put forward is that there is no clear agreement in the research literature and various police training manuals about the definition of some question types, specifically open and closed questions, which may, in turn, cause confusion (see Oxburgh, et al., 2010 for a review). However, we would suggest that in addition to this, there are three additional factors that could help explain the frequent use of closed questions: (i) Control; (ii) Speed, and; (iii) Power.

\section{Control}

Whoever is asking the questions must remain in control of the interview. When faced with something that is viewed as repulsive or something that is not understood, many will attempt to control the situation. Asking mostly closed types of questions puts the interviewer in control and gives the interviewee very little room to explain him or herself. In the case of sex offenders, officers may find the details that are disclosed by the suspected offender as distasteful so, to counteract this, they may try to limit their emotional exposure to them. 
Speed

An interview that mainly seeks confirmation of known facts by way of closed questions is faster to conduct than other forms of investigative interviewing (e.g., the cognitive interview). Conducting a speedy interview reduces physical (and psychological) exposure to a suspected offender, whom an interviewing officer may dislike. Moreover, the demands of contemporary police officers to conduct interviews with speed may well make the interviewing officers more inclined to use closed questions.

\section{$\underline{\text { Power }}$}

Rather than showing empathy to the suspected offender, some interviewers may seek some kind of persecution of the offender (e.g. a paedophile). If the questions asked are closed in nature, there is no opportunity for the interviewee to try and rationalise his/her behaviour; plead his/her case; relive the events in a way that excites him/her; or stick to his/her lie script. Arguably, this may reduce his/her standing in the interviewing officers' eyes and, although subtle, it takes away the suspected offender's perceived power.

We must also be cognizant of the fact that the nature of the open-ended discourse expected by interviewing officers is somewhat unfamiliar (Wright \& Powell, 2006). For example, in everyday interactions, we do not generally converse using open questions, rather we use a 'question-and-answer' style of conversation, using closed and other forms of questions as a matter of routine 
(Wright \& Powell, 2006). An interview situation is a complex, interactional process between two or more persons, which can be affected by numerous factors (Dickson \& Hargie, 2006), hence the need for extensive classroom and work based training and assessment for interviewing officers.

\section{Interview training}

There is no doubt that training for investigative interviewing has been enhanced considerably during the past two decades, especially in England and Wales $^{2}$, and is testament to the Police Service wishing to enhance their ability to improve officers' interviewing skills. Since the introduction of the PEACE model of interviewing in 1993, there have been many studies which have critically evaluated police interviewing skills. These have considered the impact of the information gathering approach to investigative interviewing (including training), the various skills that effective interviewers display, and the structure of good quality interviews with suspected offenders (e.g. Baldwin, 1993; Bull \& Cherryman, 1995; Cherryman, 2000; Clarke \& Milne, 2001; McGurk, Carr \& McGurk, 1993; Milne \& Bull, 1999; Stockdale, 1993; Williamson, 1993) and witnesses (e.g. Bruck, Ceci, Francouer \& Renick, 1995; Ceci \& Bruck, 1995; Dent \& Stephenson, 1979; Goodman \& Aman, 1990; Lamb, et al., 1996b; Lamb, Sternberg, Orbach, Esplin \& Mitchell, 2002a; Lamb et al., 2002b; Lamb, Orbach, Sternberg, Esplin \& Hershkowitz; 2002c; Loftus, 1982; Sternberg, et al., 1996).

\footnotetext{
${ }^{2}$ Although training in other parts of the UK and across the world has also doubtless improved, the present paper only focuses upon police interviewing in England \& Wales.
} 
However, in an evaluation of a three-day training programme for both social workers and police officers in England and Wales, Aldridge and Cameron (1999) found that training had little effect on the questioning style used by officers. In addition, although trainees' had attended lectures and practiced the information they had learned, they actually showed poor rapport building skills and continued to ask many inappropriate questions (e.g. leading and suggestive). This suggest that unlearning old techniques is problematic and that police officers quickly revert to their prior experiences and what they perceive to be tried and trusted interview (and questioning) styles/techniques (Wright \& Powell, 2006).

Following Clarke and Milne's (2001) national evaluation of police interviewing, a tiered structure of interviewing skills was developed in England and Wales. These were categorised as: Tier 1 - Probationer training (one week); Tier 2 Uniformed investigators and detectives (one week); Tier 3 - Specialist interviewers (victim/witness/suspect) (three weeks); Tier 4 - Investigative interview manager; and, Tier 5 - Specialist interview management. In 2007, investigative interview training (and the five tiers) was enhanced and incorporated into the Professionalising Investigations Programme (PIP), which is intended to increase professionalism of all investigators, and to establish a structured, professional approach to investigations. It is important to note, that although such enhancements in training will doubtless continue, there is a debate regarding the long-term effectiveness of current interviewing training (Griffiths \& Milne, 2006; Lamb, Hershkowitz, Orbach \& Esplin, 2008). Griffiths and Milne found that although training levels were higher one year after officers 
completed advanced training, there was a 'marked decline' (p. 187) in interviewing officer's performance (in some of the assessed criteria) between their first and last assessed interview Griffiths et al., (submitted). They argue that despite this 'marked decline', advanced training improved the skills of officers (in their sample). However, we argue that any decline in performance or ability is somewhat concerning and requires additional training.

Although empirical research (e.g. see Powell, 2002 for a review) and the PEACE model advises evaluation of interviews by officers and supervisors, this important aspect rarely gets the attention it deserves. While some aspects of training programmes may be effective in terms of teaching interviewers what they ought to do in interviews, the training appears to be having very little impact overall (Powell, 2002). One of the problems appears to be that, currently, there is no widely accepted evaluation/classification system within police organisations, or the academic literature, which provides guidelines on how to effectively analyse information gained from interviews. In line with recommendations by Powell (2002), we argue that this void must be addressed and that future research must include the long-term acquisition of interviewing skills and should incorporate the experience of both practitioners and academics to enhance the research. We must also promote and encourage: (a) a structured way of recruiting interviewers; (b) timing and frequency of refresher training; (c) training for supervisors to enable effective feedback/supervision of interviews; and (d) the revision of best practice guidelines. 


\section{Empathic interviewing style}

There is very little empirical research that has looked at the use of empathy in interviews with suspected offenders. Some police training guidelines and protocols make scarce reference to its use and/or effectiveness. For example, in the UK's guidance document on achieving best evidence (ABE) in criminal proceedings (Home Office, 2007), empathy is referred to only once, advising interviewers to, '... demonstrate a willingness to try to understand the situation from the interviewee's perspective' (p.16). However, recent research suggests that where officers showed high levels of empathy, more confessions were obtained (Holmberg \& Christianson, 2002; Kebbell et al., 2006).

Holmberg and Christianson (2002) investigated eighty-three convicted offenders' (40 sexual offenders \& 43 murderers) perceptions of their police interviews. Two factors emerged from their analysis - dominance and humanity. The dominant approach (used mostly in interviews with sex offenders) was characterized by aggressiveness and hostility, whereas the humane approach (used mostly in interviews with murderers) was characterized by officers being more friendly and co-operative. Holmberg and Christianson also found more admissions of guilt in interviews, which used the humane approach (e.g. murderers). In another study, Kebbell et al., (2006) also found that suspected offenders suspected offenders reported that they would have been more likely to confess had the police treated them with humanity and showed empathy towards them. 
Both these studies have relied on offenders' self-reports of what they may have done had they been interviewed in a more empathic manner. Both studies also relate to interviews that are confession-based, however, in England and Wales (and other parts of the world), interviews are (primarily) a search-for-the-truth and non-coercive. As such, they rely on officers obtaining good quality information that is relevant to the investigation, regardless of whether the information obtained exonerates the suspected offender. When we turn to research that focuses upon investigation relevant information (IRI) obtained from interviews as opposed to confessions, the findings are somewhat different. Using a model for measuring empathic responses in police interviews, Oxburgh, Ost and Cherryman (2010) explored the impact of empathy on the amount of IRI obtained during interviews with sex offenders.

In their study, Oxburgh et al., (2010) counted empathic opportunities, continuers and terminators presented in the interviews. An empathic opportunity was defined as, 'a statement or description from which a police officer might infer an underlying emotion that has not been fully expressed by the suspect' (Oxburgh et al., 2010, p. 12). Empathy was deemed to be present if the interviewing officer continued an empathic opportunity provided by the suspected offender. The number of opportunities, continuers, and terminators were counted in each interview (for a full review, see Oxburgh et al., 2010). They found no significant difference in the amount of IRI reported in interviews where continuers were used compared to those in which they were not. That said, there is, quite obviously, more to an empathic interviewing style than just the number of opportunities available or continuers that are counted in an interview. 
Oxburgh et al. also only analysed interviews for empathic opportunities overtly presented by the suspected offender, whereas in some interviews, officers (although not in their sample) may also use an empathic style of interviewing without any prompting from the offender (e.g. ad hoc empathy). Although these findings are interesting they require further research.

\section{Conclusion}

This paper has attempted to outline the impact of psychological theory and empirical research to investigative interviewing in recent decades. The interviewing of both suspected offenders and witnesses has been greatly enhanced, worldwide, as a consequence. We hope that we have shown that by working closely together academic research can make a difference, and influence law, policy decisions and training guidelines in order to improve practice. However, there is no room to relax and we must always 'stay ahead of the game', to ensure that this specialist area evolves in such a manner that not only continues the important practitioner/academic relationship, but which ensures that all future directions are driven by empirical research, with recourse to emergent theory. 


\section{References}

Bower, G. (1967). A multicomponent theory of a memory trace. Psychology of Learning and Motivation, 1, 230- 325.

Boon, J. \& Noon, E. (1994). Changing perspectives in cognitive interviewing. Psychology, Crime, \& Law, 1, 59-69.

Clarke, C. \& Milne, R. (2001). National evaluation of the PEACE investigative interviewing course. London: Home Office.

Clifford, B. R. \& George, R. (1996). A field evaluation of training in three methods of witness/victim investigative interviewing. Psychology, Crime, \& Law, 2, 231-248.

Dando, C., Wilcock, R., Behnkle, C., \& Milne, R (in press). Modifying the Cognitive Interview: Countenancing forensic application by enhancing practicability. Psychology, Crime, \& Law.

Dando, C. J., Ormerod. T. C., Wilcock, R., \& Milne, R. (under review). Eyewitness memory and change temporal order: Help or hinderance?

Dando, C. \& Ormerod, T. C. (2009). Effects of change temporal order technique on eyewitness memory. In N.A. Taatgen \& H. van Rijn (Eds.) Proceedings of the 
31st Annual Conference of the Cognitive Science Society. Austin, TX:

Cognitive Science Society.

Dando, C., Wilcock, R., \& Milne, R. (2009). The cognitive interview: The efficacy of a modified mental reinstatement of context procedure for frontline police investigators Applied Cognitive Psychology, 23, 138-147.

Dando, C., Wilcock, R. \& Milne, R. (2009). Novice police officers' application of the cognitive Interview procedure Psychology, Crime, \& Law, 15, 679-696.

Dando, C., Wilcock, R., Milne, R., \& Henry, L. (2009). An adapted Cognitive Interview procedure for frontline police investigators Applied Cognitive Psychology, 23, 698-716.

Dando, C., Wilcock, R., \& Milne, R. (2008). Victims and witnesses of crime: Police officers' perceptions of interviewing practices. Legal and Criminological Psychology, 13, 59-70.

Davis, M.R., McMahon, M., \& Greenwood., K.M. (2005). The efficacy of mnemonic components of the cognitive interview: Towards a shortened variant for time-critical investigations. Applied Cognitive Psychology, 19, 75-93.

Emmett, D., Clifford, B. R., \& Gwyer, P. (2003). An investigation of the interaction 
between cognitive style and context reinstatement on the memory performance of eyewitnesses. Personality and Individual Differences, 33, $343-351$.

Fisher, R. \& Geiselman, R. (1992). Memory-enhancing techniques for investigative Interviewing: The cognitive interview. Springfield: Charles Thomas.

Geiselman, R. E., Fisher, R. P., Firstenberg, I., Hutton, L., Sullivan, S. J., Avetissian, I. V., \& Prosk, A. L. (1984). Enhancement of eyewitness memory: An empirical evaluation of the cognitive interview. Journal of Police and Science Administration, 12, 74-80.

Goldsmith, M., Koriat, A., \& Pansky, A. (2005). Strategic regulation of grain size in memory reporting over time. Journal of Memory and Language, 52, 505525.

George, R. (1991). A field evaluation of the cognitive interview. Unpublished masters thesis, Polytechnic of East London.

Greenberg, M. S., Westcott, D. R., \& Bailey, S. E. (1998). When seeing is believing: The effect of scripts on eyewitness memory. Law and Human Behavior, 22, $685-694$.

Holst, V. F. \& Pezdek, K. (1992). Scripts for typical crimes and their effects on memory for eyewitness testimony. Applied Cognitive Psychology, 6, 573-587. 
Kebbell, M., Milne, R., \& Wagstaff, G. (1999). The cognitive interview: A survey of its forensic effectiveness. Psychology, Crime, \& Law, 5, 101-115.

Kebbell, M. R. \& Wagstaff, G. F. (1996). Enhancing the Practicality of the Cognitive Interview in Forensic Situations. PSYCOLOQUY, 7, witnessmemory.3.kebbell.

Lansdale, M. \& Baguley, T. (2008). Dilution as a model of long-term forgetting. Psychological Review, 115, 864-892.

Longford, G. P. (1996). The use of the cognitive interview by police officers trained on the national investigative interviewing course. Unpublished MSc dissertation. Institute of Police and Criminological Studies, University of Portsmouth.

Mandler, J. M. (1984). Stories, scripts, and scenes: Aspects of schema theory. Hillsdale, NJ: Lawrence Erlbaum.

Milne, R. \& Bull, R. (1999). Investigative interviewing: Psychology and practice. Chichester: John Wiley \& Son.

Memon, A., Cronin, O., Eaves, R., \& Bull, R. (1996) An empirical test of the 
mnemonic components of the Cognitive Interview. In G.M. Davies, S. Lloyd-Bostock, M. McMurran \& C. Wilson (Eds.), Psychology, Law \& Criminal Justice. Berlin: De Gruyter.

Memon, A., Holley, A., Milne, R., Köhnken, G., \& Bull, R. (1994). Towards understanding the effects of interviewer training in evaluating the cognitive interview. Applied Cognitive Psychology, 8, 641-659.

Oxburgh, G. E., Ost, J., \& Cherryman, J. (2010, in press). Police interviews with suspected child sex offenders: Does use of empathy and question type influence the amount of investigation relevant information obtained? Psychology, Crime and Law.

Oxburgh, G. E., Myklebust, T., \& Grant, T. (2010). The question of question of question types in police interviews: A review of the literature from a psychological and linguistic perspective. International Journal of Speech, Language and the Law, 17, 45-66.

Pezdek, K., Wheatsone, T., Reynolds, K., Askari, N., \& Dougherty, T. (1989). Memory for real-world scenes: The role of consistency with schema expectation. Journal of Experimental Psychology: Learning, Memory, and Cognition, 15, 587-595.

Polyn, S. M., Norman K. A., and Kahana M. J. (2008). A context maintenance and 
retrieval model of organizational processes in free recall. Psychological Review, 116, 129-156.

Rosenbluth-Mor, M. (2001). Accuracy and quantity in memory reports: the effects of context reinstatement. Unpublished masters thesis, University of Haifa, Israel.

Schank, R. C. \& Abelson, R. P. (1977). Scripts, plans, goals, and understanding: An enquiry into human knowledge structures. Hillsdale: Erlbaum.

Tuckley, M. R. \& Brewer, N. (2003). How schemas affect eyewitness memory over repeated retrieval attempts. Applied Cognitive Psychology, 17, 785-800.

Whitten, W. B., \& Leonard, J. M. (1981). Directed Search Through Autobiographical Memory. Memory and Cognition, 9, 556-579.

Wright, A. M. \& Holliday, R. E. (2005). Police officers' perceptions of older eyewitnesses. Legal and Criminological Psychology, 10, 211- 223. 